\title{
«O DOMINIO DA CASA DE SAN FIZ DE ASMA: EVOLUCIÓN E INVERSIÓN DUN DOMÍNIO FIDALGO DURANTE O ANTIGO RÉXIME»
}

\author{
por \\ VITOR MANỤEL MIGUEZ
}

Tradicionalmente enfocada dende unha perspectiva erudito-xenealóxica, a história dos pazos galegos adoeceu de perspectivas económico sociais acordes coa renovación historiográfica dos últimos decénios ${ }^{1}$. Porén tais aportacións, independentemente do mérito de autores como BOUZA BREY ou FERRO COUSELO, pouco mais aportaron que a confirmación das teorias do Seminario de Estudos Galegos verbo da fundación de boa parte dos morgados fidalgos a fins do século XVI², obviando absolutamente perspectivas mais extensas relativas ao tema. Foi por iso polo que as investigacións de Ramón VILLARES encol da Casa de Lagariños, cobriron de xeito absoluto un dos valeiros mais patentes da historiografia galega ${ }^{3}$. Nas suas pescudas, o profesor vilalvés confirmaba escritos e teorias

\footnotetext{
${ }^{1}$ Dentro dos numerosos historiadores desta corrente só contadas excepcións forneceron un material a salientar. Vid. por exemplo as vastas aportacións de VÁZQUEZ SEIJAS, M; Fortalezas de Lugo y su provincia; Lugo, 1955-57 CRESPO POZO, J; Blasones y linajes de Galicia; Ed. de los Bibliófilos Gallegos \& Monasterio de Poio, Santiago, 1958-85; e as mais integrais de BOUZA BREY, F; «El señorío de Villagarcia desde su fundación hasta su marquesado, 1461-1655»; In C.E.G. Anexo XV, Santiago, 1965; e FERRO COUSELO, X; «Gente llana con ventura, Los Boanes»; In Boletin Auriense 2, Museu Arqueolóxico, Ourense, 1972.

${ }^{2}$ Vid. VV.AA; Terra de Melide; Santiago, 1933.

${ }^{3}$ vid. VILLARES, R; La propiedad de la tierra en Galicia; Siglo XXI, Madrid, 1981.
}

"CUADERNOS DE ESTUDIOS GALLEGOS", Tomo XLII, Fascículo 107, Santiago 1995. 
salientadas polos tratadistas decimonónicos, nas cais se sinalava ao subforo das institucións eclesiásticas como o medio principal de formación patrimonial da fidalguia emerxente ${ }^{4}$; conclusión que mesmo deu orixe á introdución en Galicia do concepto de clase média 5 .

A fortuna desta denominación perpetuou a expresión middlemen ou «señores medianeros» acuñada por MONTERO RIOS en $1886^{6}$, e mesmo conservouse hoxendia ao traverso de conceptos como o de «hidalguia intermediaria» ${ }^{7}$. A obra de VILLARES non fixo senón insistir outravolta no carácter intermediario da fidalguia galega, e con ela, dos seus sistemas de medre económico ${ }^{8}$, tendencia que se ben semella ser certa para determinados dominios como o de Lagariños, foi minoritaria no caso doutros.

${ }^{4}$ Este feito foi o que orixinou unha publicística voraz verbo da fidalguia e da institución foral no século XIX. Son interesantes as referéncias de Jacobo GIL VILLANUEVA ao respecto:

«...una idea ocurrio, inocente en su primera concepcion, maldecible en su realidad. Sus elementos son el egoismo de una parte; la irreflexion e la otra. Esos elementos combinados han creado los subforos....».

E mesmo as mais directas de Gumersindo BUJÁN:

«...abuso y abuso muy lamentable fue el de los subforos, pues la renta que se imponía sobre las tierras, en beneficio de verdaderos parásitos de la propiedad, crecia considerblemente en cada transmisión (...) siquiera los monasterios y conventos, con sus ambiciones y egoismo, habian concedido las tierras por módicas pensiones; pero los hidalgos y señores que a la sombra de aquellas corporaciones adquirieron posición y tierras, las transmitieron á otros foreros imponiendoles pensiones subidísimas...». Vid. GIL VILLANUEVA, J; «Propiedad foral: Galicia»; Revista Económica I, S.E.A.P. Santiago, 1859, p.66; et BUJÁN, G; De la propiedad y los foros; Ourense, 1902, p. 182.

${ }^{5}$ Vid entre outros: PIÑEIRO SOMOZA, R; « ¿Son perjudiciales los foros en Galicia?; In Revista General de Legislación y Jurisprudencia XIII, Madrid, 1863, p.116 / JOVE Y BRAVO, R; Los foros en Asturias y Galicia; Oviedo, 1876, p.17 / DÍAZ DE RÁBAGO, J; «Sobre foros» -prólogo a un libro de Alfredo Vicenti-; In Díaz de Rábago, Obra Completa T.VII, S.E.A.P. Santiago, 1900, p.233 / PÉREZ PORTO, José; El derecho foral de Galicia; A Coruña, 1915, p.69 / BERNALDO DE QUIRÓS, C \& RIVERA PASTOR, F; El problema de los foros en el NO de España; Instituto de Reformas Sociales, Madrid, 1923, p.28 / PLANELLAS, J. (Recopilador); «Actas del Congreso Agrícola Gallego»; In Revista Económica V, S.E.A.P. Santiago, 1864.

${ }^{6}$ Vid. MONTERO RIOS, E; Proyectos de ley de expropiación forzosa, redención de censos y foros y crédito agrícola; Madrid, 1886, p.76

7 Vid. EIRAS ROEL, A; «Prólogo» [A M ${ }^{\mathrm{a}}$ del Carmen Quintáns en El dominio de San Martin Pinario]; Universidade de Santiago, 1972, p.12

${ }^{8}$ Para Villares a interposicion entre outros domínios e a propriedade da terra é sen dúvida a via mais frecuente de adquisición de domínios por parte da fidalguia. VILLARES, $\mathrm{R}$; La propiedad de la tierra...; op cit. p. 81

"CUADERNOS DE ESTUdiOS GALLEGOS", Tomo XLII, Fascículo 107, Santiago 1995. 
A este respecto, o dominio da Casa de San Fiz de Asma afastase notoriamente deste modelo por realizar grande parte da sua expansión patrimonial a traverso dun importante proceso de merca de terras. As mercas de terras constituiron unha estratexia xeral dentro da formación dominial da maioria dos domínios da pequena nobreza galega, como tamén aconteceu coa Casa de Lagariños, pero a sua consideración como estratexia menor se invalida para o dominio chantadino que estamos a estudar na nosa tese doutoral. Urxe, xa que logo, apresentar as conclusións ao respecto a fin de salientar a importáncia que tivo este tipo de inversión económica na formación da fidalguia galega. Tal obxectivo apoiase na documentación particular do Marquesado de «San Martín» de Ombreiro", conxunto documental descatalogado e bastante desigual na sua composición, da que sobresaen un amplo número de protocolos notariais nos que se alicerzaron fundamentalmente os nosos dados, previamente aos cais expomos unha breve história da casa.

O dominio de San Fiz ven dado da confluencia de duas liñas familiares (ESQUEMA N ${ }^{\circ} 1$ ); unha era a do coengo lucense Gómez Núñez de Gayoso, posuinte na cidade de Lugo e arredores dunha ampla propriedade raíz da que salientaban os coutos xurisdicionais de Ombreiro e Parada. Maria de Neira e Prado, a sua neta, receberá íntegras as suas propriedades a traverso dunha mellora de tercio e quinto en 1611, canalizandoas ulteriormente ao patrimonio da Casa de San Fiz por mor do seu matrimonio con Francisco Rodríguez Varela. Dous dos seus fillos foron beneficiados pola fundación de dous vínculos por parte do seu avó, o escribano Estevan Tenreiro en 1614, dividindo as propriedades da casa en dous grupos en torno a Chantada e Lugo. Finalmente, a morte dun dos netos unificaria o patrimonio da casa. Este, acrescentado con dotes, subforos, pero fundamentalmente con mercas de terras, expandiriase notablemente en 1762, cando produxose a incorporación patrimonial da viciña Casa de Tarrio (ESQUEMA No2); pero non acadaria a sua máxima extensión ata cruzada a fronteira secular, onde logo do casamento do vinculeiro Benito Maria de Prado con Maria Josefa de Neira e Ulloa, a Casa de S.Fiz incorporaria a impresioante cantidade de 10 solares, causa última do nomeamento en 1817 de José Maria de Prado como Marqués de «San Martín de Ombreiro».

\footnotetext{
${ }^{9}$ Actualmente un conxunto de cáseque 100 legaxos depositados no Fondo de Familias Particulares do A.R.G.
}

"CUADERNOS DE ESTUdios GALlEGOS", Tomo XLII, Fascículo 107, Santiago 1995. 


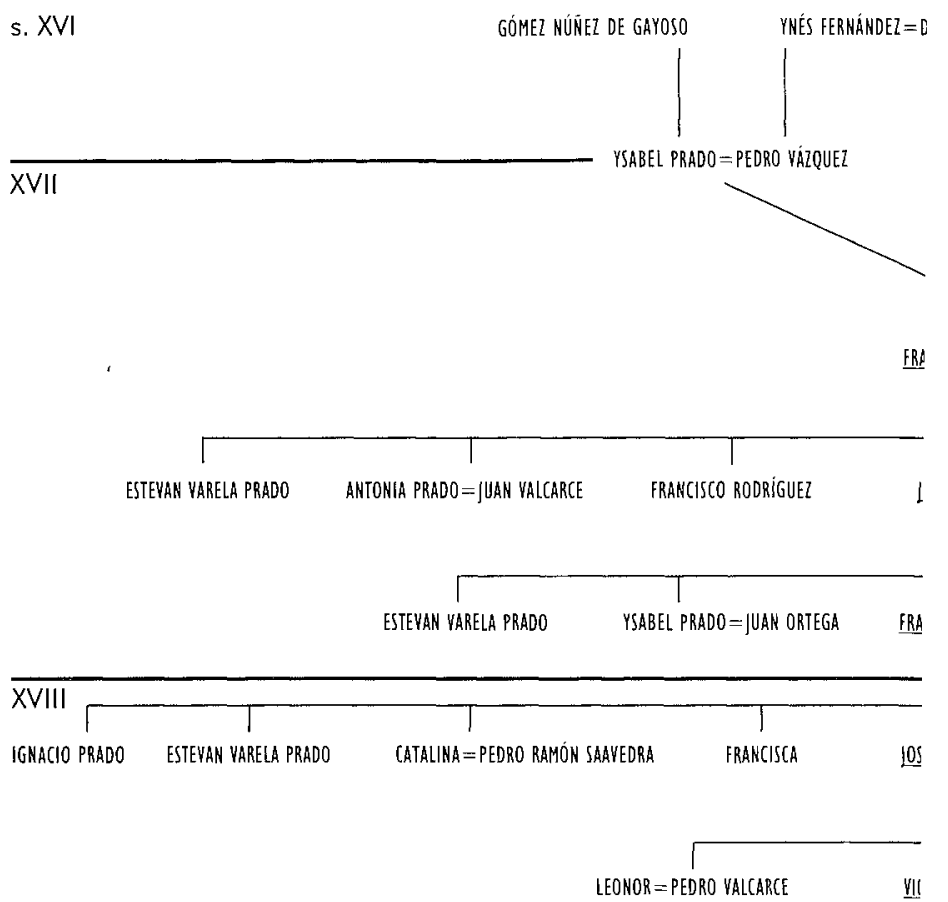

BE

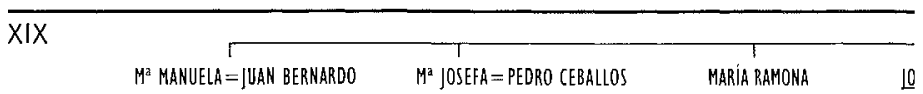

ESQUEMA 1. XENEALOXIA DA C 


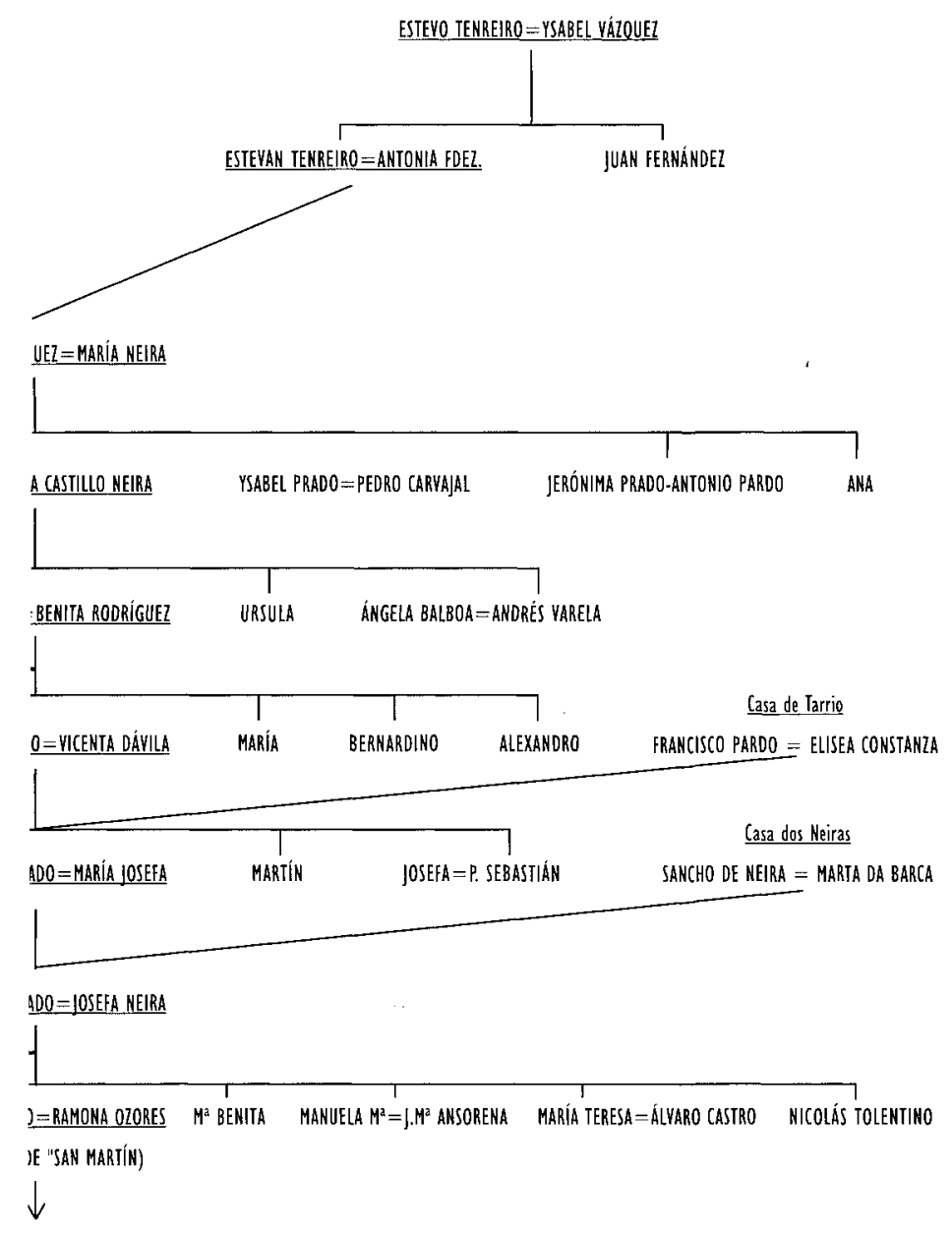

;SAM FIZ DE ASMA (ss. XVIII-XIX) 


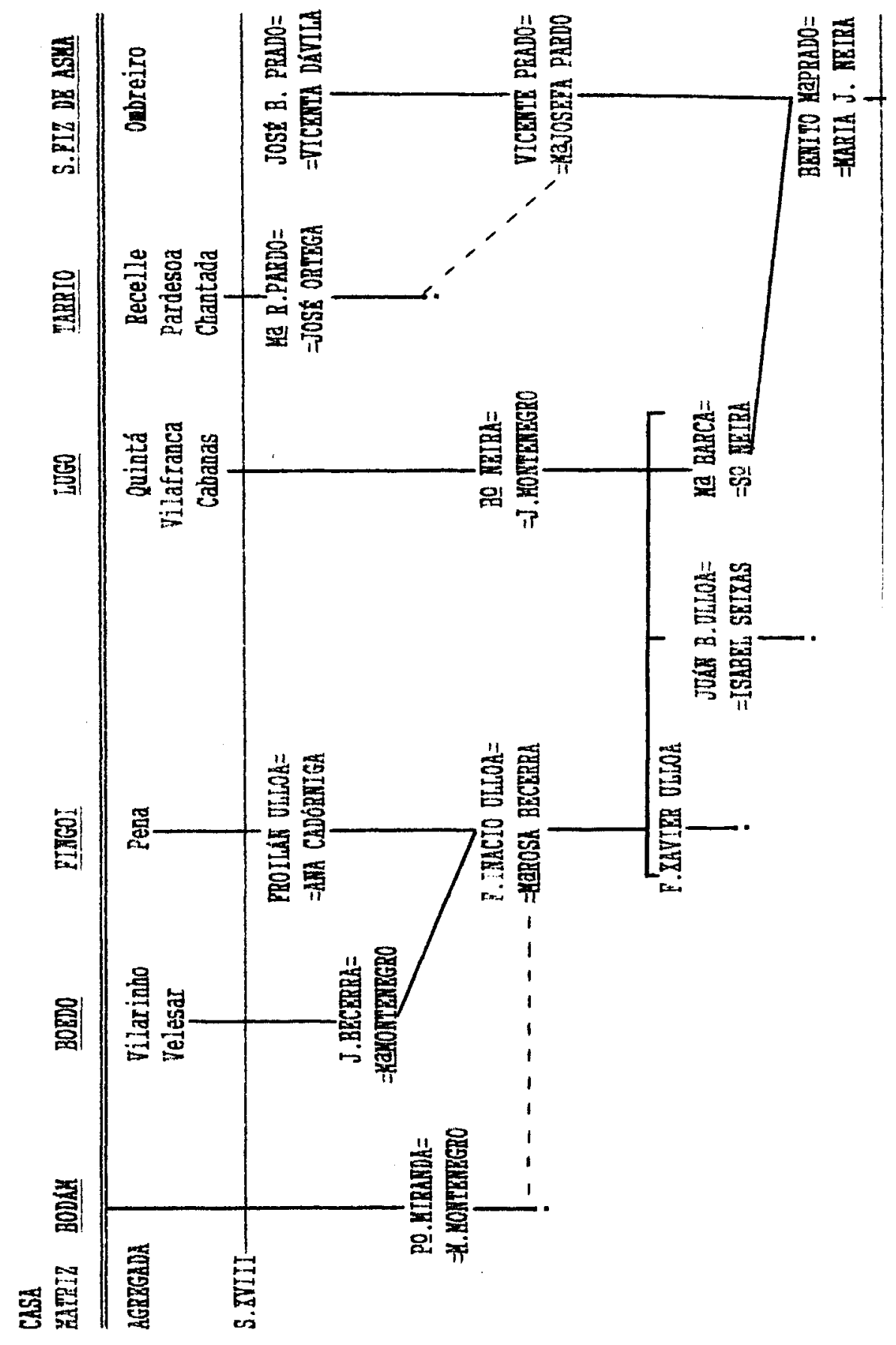


ESOUEMA : AGREGACIONS DA CASA DUS ULLUAS UE LUGU

J. YARTA PRADO=

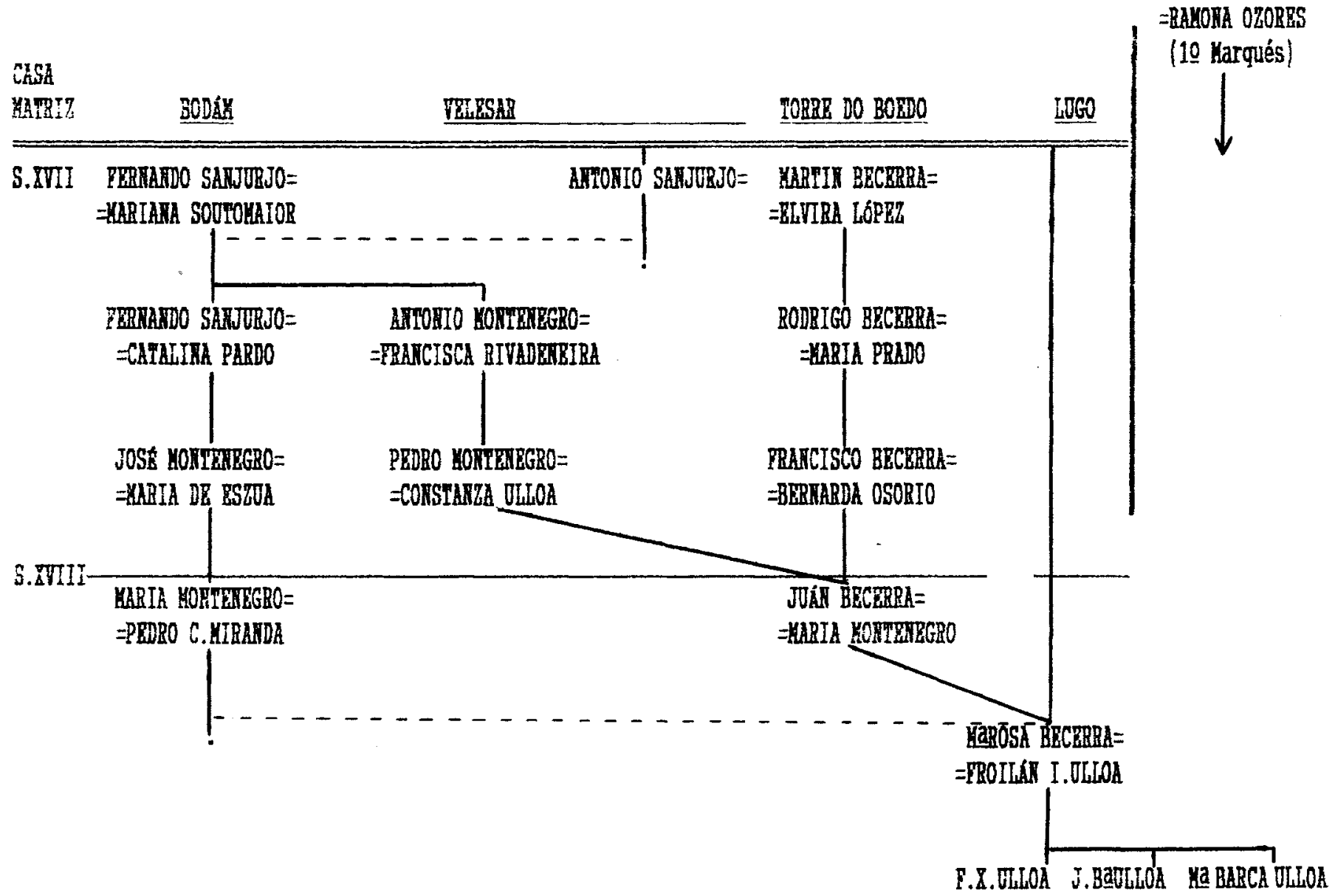

Esquema 2: INCORPORACIÓNS VINCULARES DA CASA DE S. FIZ (s. XVIII) 


\section{FORMACIÓN DOMINIAL}

Ainda que a este respecto non podemos aventurar cifras exactas polo desigual da documentación, sabemos claramente que as propriedades de San Fiz provintes de subforos difícilmente superan o 3\% e nunca o $5 \%$, dividindose o resto quer en património obtido por via matrimonial quer en mercas de terras, foros, rendas e similares. Non imos entrar agora nos mecanismos de reprodución social da família, encauzados fundamentalmente no matrimonio e indubidablemente os mais importantes no engrosamento económico da familia (como asi amostrouse coas anexións vinculares de fins do s.XVIII), pois consideramos que son estratéxias sociais de grande trascendéncia, pero estas veñen dadas en última instáncia por unha posición derivada das xenuinas e estritas estratéxias económicas, as mercas. Estas deben ser analisadas diacrónicamente ao traverso das sucesivas xeracións da familia.

Estevo Tenreiro Varela en Chantada, foi a persoaxe que comezou a fervenza de mercas, efectuando unha ampla extensión dominial en base a 163 mercas de terras e rendas no periodo de 55 anos que abrangue o troco de século (1580-1635). Este petrucio foi o artífice da primeira expansión do dominio non só por extendé-la xeografia patrimonial nos arredores de S. Fiz, senón tamén por ser el quen determinou a fundación vincular, feita ás claras pensando na incorporación dos bens de Ombreiro e Lugo, de aí que asignara un vínculo ao seu neto Francisco Félix de Prado, e outro ao seu irmán José Arias de Gayoso y Prado, coas propriedades de San Fiz e Lugo respectivamente. Estevo Tenreiro comentara na escrita de fundación que os descendentes dos respectivos vínculos casaran entre si coa fin de manter unido o património, pero non foi necesária tal estratéxia, habida conta da morte do primeiro vinculeiro sen descendéncia.

Vemos, xa que logo, como foi o último tramo do século XVI a época na cal se urde a trama que tece o primeiro petrucio coa fin de consolidala sua preeminéncia. Este señor combinou catro factores á hora de engrandecela casa: $1^{\circ}$ ) A sua merca de de terras, á orde de 2,96 por ano, que lle permitiu negociar un matrimónio vantaxoso; $2^{\circ}$ ) O casamento do seu fillo coa erdeira do património do coengo lugués Gómez Núñez de Gayoso; 3) A dobre fundación vincular baseada en critérios xeográficos en aras a unha expansión dominial diferencial; 4) O favorecimento do casamento colateral a fin de non dividilo património.

O homólogo de Estevo Tenreiro en Lugo era Gómez Núñez de Gayoso. Como xa vimos, este non era integrante directo da família, pero a sua

"CUADERNOS DE ESTUdios GALLEGOS", Tomo XLII, Fascículo 107, Santiago 1995. 
actividade non só revertiria finalmente na casa de San Fiz, senón que amais constitue un exemplo similar ao de Estevo Tenreiro no senso de que a sua política de mercas ten unhas pautas procedimentais e uns obxectivos similares. Ao igual que este, o coengo comezou outra fervenza de mercas na segunda metade do XVI, nunha zona distinta á chantadina, pero cun ritmo cáseque idéntico ao que ollabamos na mesma, ou sexa un número de 60 en 22 anos, o que supon un índice de actividade de 2'72 (TAVOA $\mathrm{N}^{\circ} 1$ ). O proceso de consolidación patrimonial nos seus coutos xurisdicionais o realizou Gómez Núñez de xeito intensivo, de sorte que 21 mercas -quer dicer, o 39,6\%- fixoas no couto de Ombreiro, mentres que 13 delas $-21,6 \%$ - se efectuaron no de Parada, de forma que un total do $56,6 \%$ das suas inversións foron centradas nas lindes dos seus coutos xurisdicionais, realizandose o resto das adquisicións en zonas próximas a estas ou á cidade de Lugo (MAPA $\mathrm{N}^{\circ} 1$ ).

As inversións no eixo de Lugo-Ombreiro-Parada se continuarian cos descendentes do coengo. Asi, Pedro Vázquez de Neira actua nesta zona entre 1579 e 1601, efectuando un total de 39 mercas con unha média anual de 1,77. Esta seria a última xeración denantes da unión da liña familiar con San Fiz de Asma. Esta cristalizará no matrimonio entre Francisco Rodríguez Varela e Maria de Neira e Prado, quenes tan só realizaron a exigua cantidade de 26 mercas durante o seu matrimónio. Esta baixa no ritmo de adquisicións poderia ter a sua explicación na política fundacional da familia. Lembremos que os vínculos fundados por Estevo Tenreiro Varela eran dous e foran asignados a Francisco Rodríguez Varela -referimonos agora a un fillo do mesmo nome do proprio Francisco Rodríguez- e ao seu irmán José Arias de Prado; feito que xunto coa morte prematura do primeiro, poderia explicar a pouca importancia do seu pai na política adquisitiva.

Tanto é asi que a xeración de José Arias e a sua muller, Maria del Castillo, seria a que definitivamente expandiria o patrimonio familiar, efectuando un total de 249 mercas entre 1629-1694 que implican unha média de cáseque catro -3,83- por ano. Nestas inversións se continua insistindo na zona dos coutos xurisdicionais -un $25 \%$ das mercas fanse neles- asi como en Lugo, pero neste caso diversificando a xeografia dominial ao traverso de novas aldeas abeirantes coa riveira. Nos achamos nestes casos con inversións pequenas e a veces pontoais, que a diferencia da centuria precedente non se concentran en zonas particulares, como acontecia con Ombreiro ou San Fiz de Asma.

Nesta época é importante resaltalo importante rol xogado polo benefi-

"CUADERnOS DE ESTUdios GALlEGOS", Tomo XLii, Fascículo 107, Santiago 1995. 


\begin{tabular}{|c|c|c|c|c|}
\hline TOULE & TilerotS & $\overline{10}$ & PERTDDO & IIIS \\
\hline Gómez Núñez Gayoso (F) & 60 & 2,72 & $1556-1578$ & 226.704 \\
\hline Juán Fernández (F) & 11 & 0.70 & $1552-1572$ & 38.709 \\
\hline Pedro Vázquez Neira (F) & 39 & 1,77 & $1579-1601$ & 130.953 \\
\hline Estevo Tenreiro Varela & 163 & $2 ' 96$ & $1580-1635$ & 1.757 .464 \\
\hline Francisco Rodríguez & 26 & 0.55 & $1607-1654$ & 142.499 \\
\hline $\begin{array}{r}\text { José Arias de Prado e } \\
\text { Maria del Castillo } \\
\end{array}$ & 249 & 3,83 & $1629-1694$ & 2.877 .277 \\
\hline Francisco Félix Varela & 17 & 1,7 & 10301544 & 134.853 \\
\hline "Abad de Lousada"-1 (F) & 18 & 1,1 & 1643-1659 & 119.663 \\
\hline "Abad de Lousada"-2 (F) & 33 & 1,73 & $1659-1678$ & 475.726 \\
\hline Francisco Arias Varela & 61 & 1,60 & $1660-1698$ & 750.296 \\
\hline José Benito Prado Lemos & 163 & 4,52 & 1698-1734 & 2.163 .891 \\
\hline "Abad de Lousada"-3 (F) & 5 & $0^{\prime} 27$ & $1714-1732$ & 60.136 \\
\hline María Josefa Pardo & 12 & $0^{\prime} 42$ & 1764-1792 & 162.000 \\
\hline $\begin{array}{lllll}\mathbf{T} & 0 & \mathbf{T} & \mathbf{A} & \mathrm{L} \\
\end{array}$ & 857 & $1,836 \mathrm{Med}$ & $1580-1792$ & - \\
\hline
\end{tabular}

(F) Familiares

TAVOA 1: NÚMERO DE MERCAS E ACTIVIDADE DE VINCULEIROS E FAMILIARES 


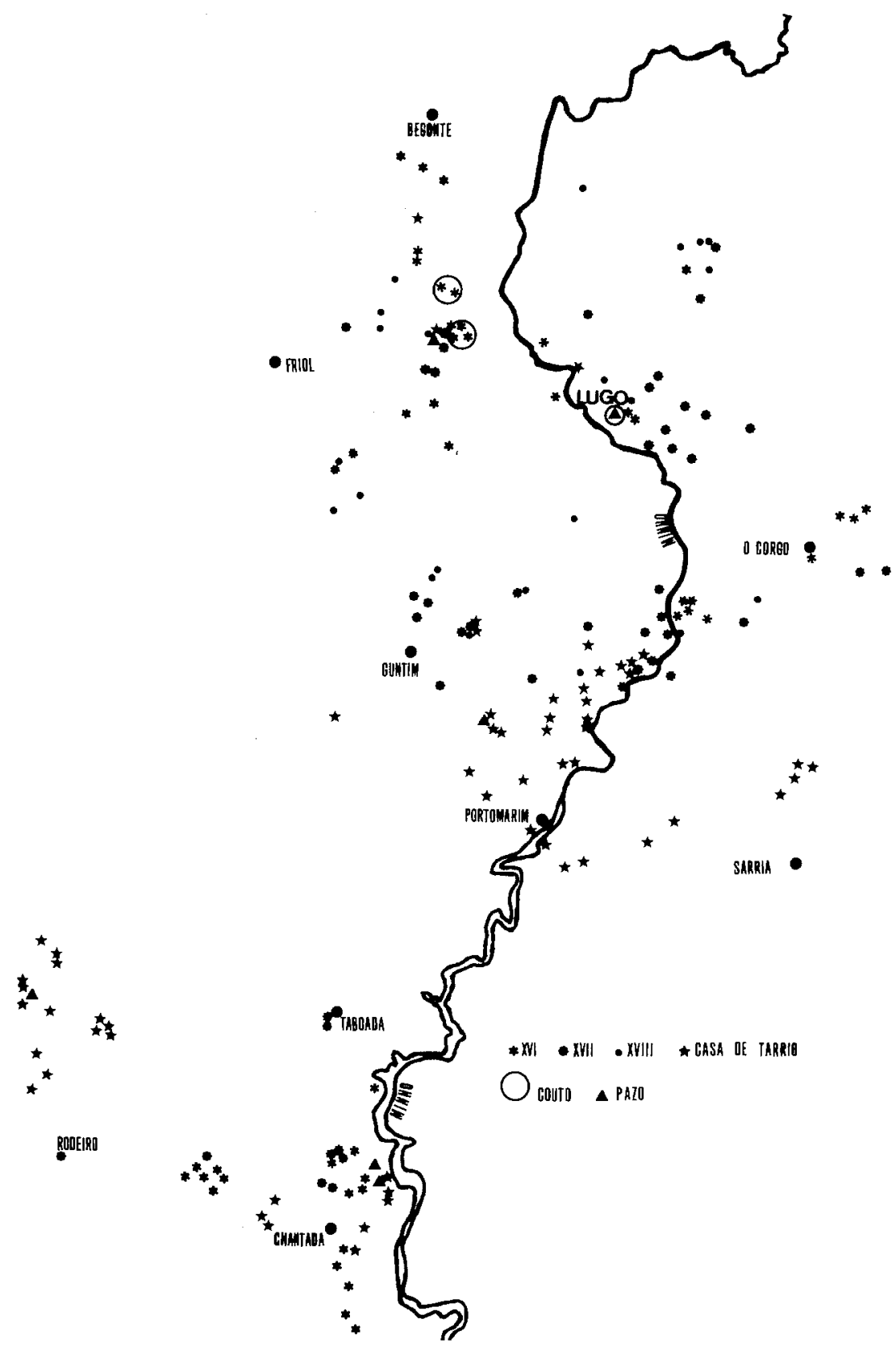

MAPA 1. CASA DE S. FIZ. MERCAS 
cio familiar de Santiago de Lousada, que situado ao sul de Chantada foi ocupado sucesivamente polo irmán e o fillo de Maria del Castillo, Esteban Varela e Prado, ámbolos dous do mesmo nome. Cando se consulta o arquivo da familia comeza a ser familiar a expresión:

«..venta que realiza X a Esteban Varela y prado en nombre de Maria del Castillo y Neira...»,

o que alén de indicar o rol inversor dos abades de Lousada, salienta un feito de grande trascendencia: a sua actuación como representantes da familia no proceso de merca de terras. Emporiso os tres abades que temos documentados efectuaron 18 mercas entre 1643 e 1659; 33 entre 1659 e 1678 e 5 entre 1714 e 1732, todas elas na zona de Chantada-San Fiz.

Os datos nos amostran, xa que logo, que dun xeito consciente os vinculeiros do século XVII invertiron masivamente no area luguesa, delegando a actividade no sul da provincia aos abades de Santiago de Lousada, delegados patrimoniais dos señores e evidentemente moito mais vinculados a estes que ao estamento que en teoria representaban. Estes comportamentos teñen un claro parangón nos resultados que tirou Baudilio Barreiro na comarca do Xallas. Neles xa destacou o «papel de mercadores de terras e directores de orquestra da política vincular» por parte dalguns cregos, o cal exemplificariase no vínculo de Álvaro Sampaio, fundado no 1609 e ao que se agregou tódala propriedade raiz adquirida polos cregos segundóns ao longo da sua vida, facendoo:

«...de buena gana, porque la costumbre, el afecto y la consideración del supremo interés familiar acallaban los instintos egoistas...» ${ }^{10}$.

Para a Casa de San Fiz, nesta época a expansión dominial foi brutal, correspondendolle a José Arias e Maria del Castillo un total do 29\% das mercas efectuadas pola familia. Tal tendencia reflictese claramente nos GRÁFICOS 1 e 2, nos que o ascenso entre 1640 e 1670 supera con creces as rectas anteriores, protagonizadas tanto pola casa de Ombreiro como por Estevo Tenreiro Varela. A magnitude da recta de tendencia seria ainda

${ }^{10}$ In BARREIRO MALLÓN, B; La jurisdicción de Xallas en el...; op cit, 1977, p. 561 .

"CUADERNOS DE ESTUDIOS GALlEGOS", Tomo XLII, Fascículo 107, Santiago 1995. 


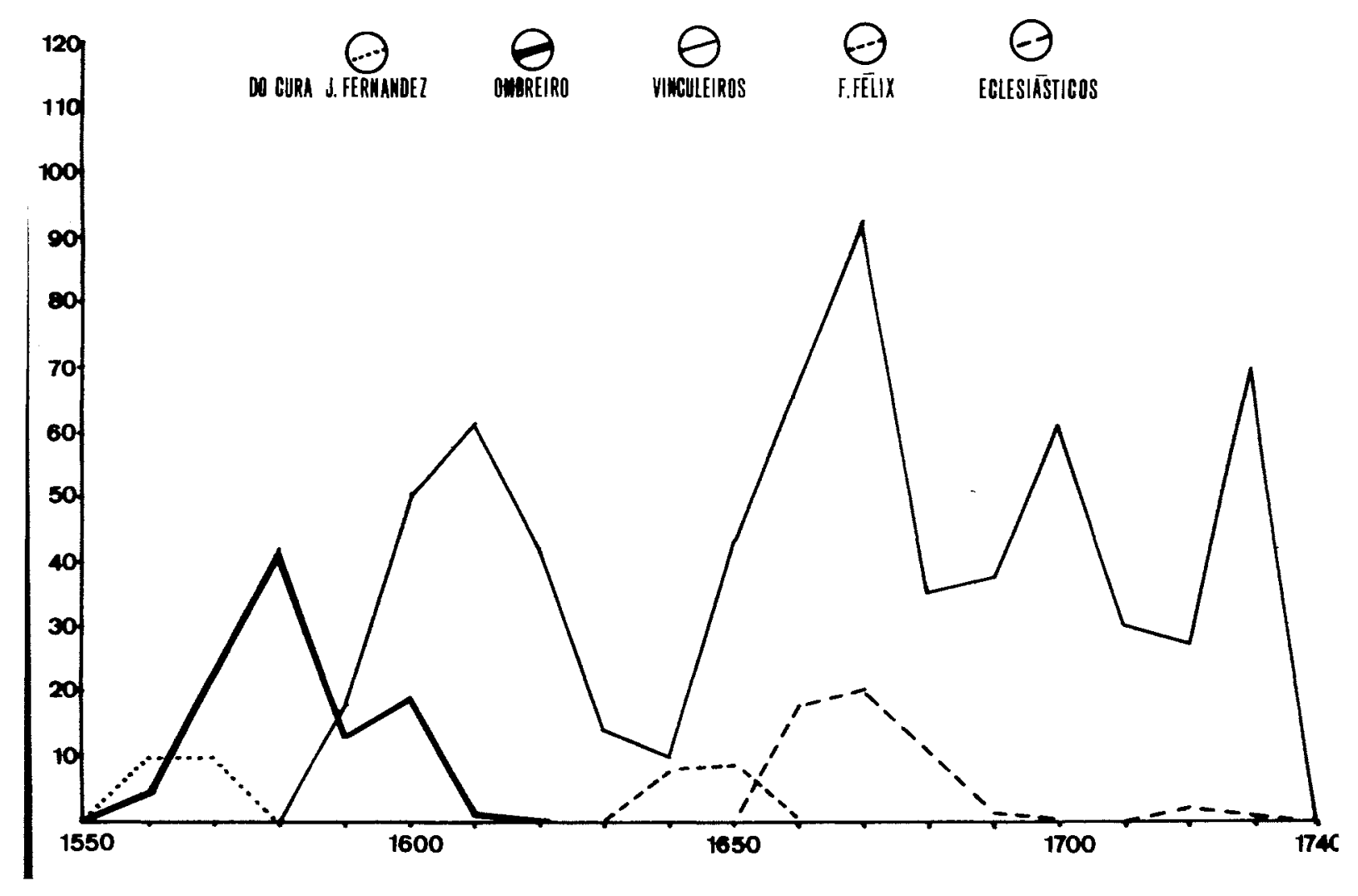

GRAFICO 1. MERCAS DA CASA S. FIZ. 1550-1740 


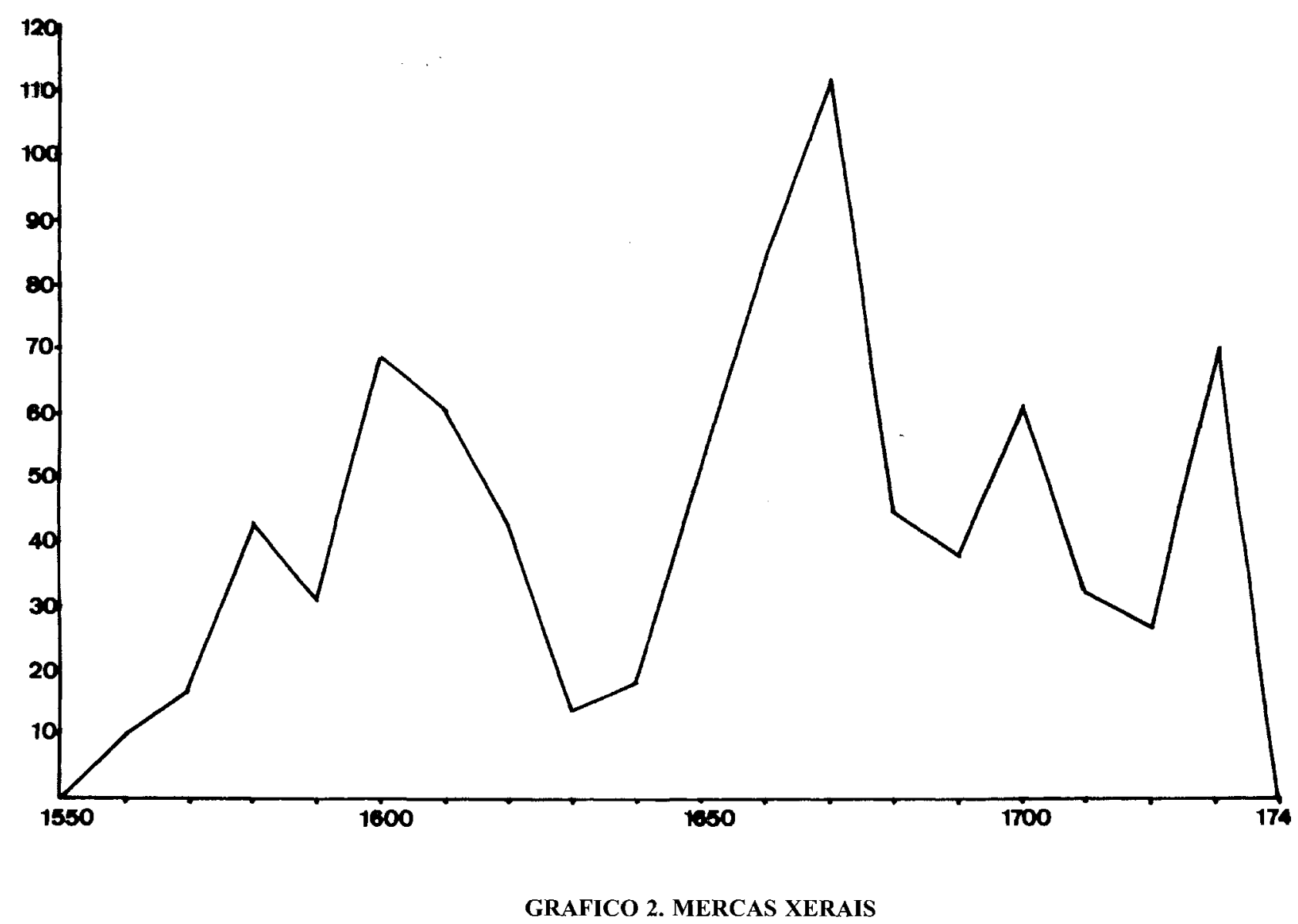


mais esaxerada de computar na mesma as inversións dos eclesiásticos de Santiago de Losada, que inserimos no gráfico a traverso dunha liña discontinua longa. O século XVII remataria con estas trazas e coa actuación do fillo de José Arias e Maria del Castilo, Francisco Arias, quen con unha média de 1,60 mercas por ano entre 1660 e 1698, representa un pequeno colofón ao século XVII, claramente protagonizado pola actividade dos seus pais, tan intensa como longa en anos.

Nas centurias do XVI e XVII efectuouse a expansión e consolidación definitiva do dominio, asinandose mais do $75 \%$ da documentación. foi, xa que logo, nesta etapa inicial e média da casa cando tivo a sua etapa dourada a nivel de inversión, e neste senso a nosa periodización coincide en parte coa efectuada por Villares para Lagariños, só que cun retraso de 50 anos pois se ben é certo que o tramo 1580-1610 se amostra en ámbolos dous casos como un momento óptimo na actividade desenrolada polos 2 pazos, a terceira etapa da que fala Villares, e que chegaria ata o 1650 , no noso caso alongase prácticamente deica o 1700 .

Poderiase falar de unha liña relativamente continuista na política desenrolada pola familia no século XVIII, centuria na que sobresae outra personalidade senlleira: José Benito de Prado y Lemos (Vid. DOCUMENTO), home que capitaneou a expansión mais grande da historia familiar, non só pola inxente cantidade de propriedade raiz adquirida, senón tamén por selo programador da primeira absorción vincular da familia. No relativo á sua actividade, esta foi a mais intensa, ascendendo a 4,52 mercas anuais entre 1698 e 1734 . Nesta época nos atopamos outravolta coa ampliación do rádio de influéncia económica do dominio, extendendose nos arredores do Miño deica Portomarin, e ancheando notoriamente o radio de influencia da Casa, claramente desbordado do primitivo núcleo de LugoOmbreiro e San Fiz de Asma.

No relativo ao resto do século, non merece maiores consideracións por mor do reducido da actividade inversora, tan só un pouco destacable no caso da seguinte vinculeira, Maria Josefa Pardo, muller de Vicente Maria de Prado, da cal temos documentados 12 protocolos de merca que constituen un escaso $1,40 \%$ total. Estas foron as únicas mercas deses anos habida conta que o seu marido foi absolutamente inactivo ao respecto. Cal é a explicación a tan gordo baixón?; evidentemente debense de buscar nos grandes problemas que a irmá de Maria Josefa Pardo, vinculeira do pazo de Tarrio, tiña para acadar descendencia, o que situaba á muller de Vicente Maria de Prado como virtual sucesora. A corroboración desta realidade non se produce ata 1789 , onde o testamento do seu cuñado, 


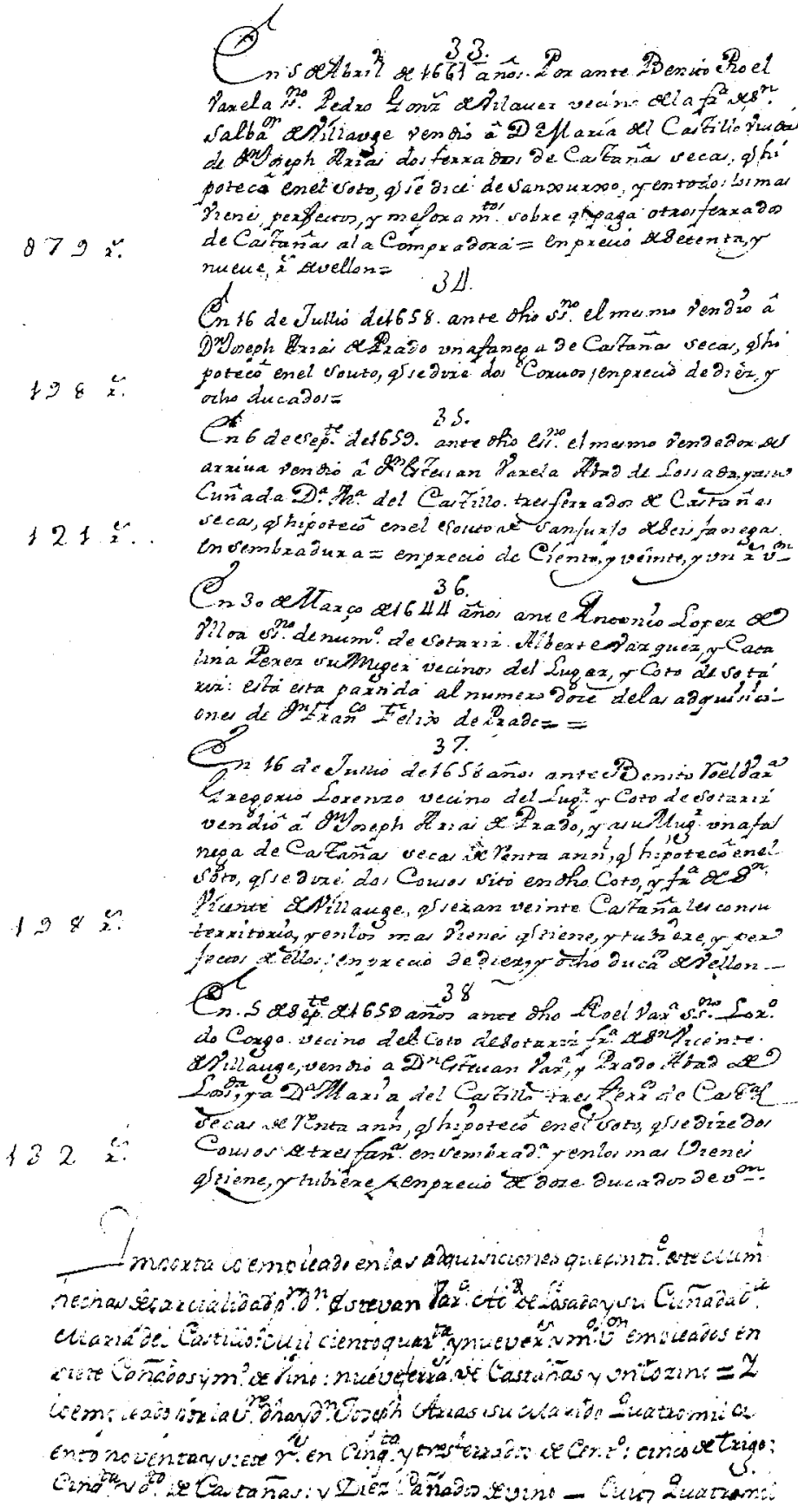


Juán Bautista Torres, declaraba herdeira á sua muller por falla de descendencia; asignado esta un ano depois por herdeira á sua irmá Maria Josefa Pardo. Coidamos que isto debe ter sido en conta á hora de valorar na sua xusta medida a cativa política inversora da segunda metade do século XVIII e a grande incidencia da expansión dominial na zona da capital, deixando de lado o núcleo chantadino, que neste século tan só se engrosa por mor da fusión coa Casa de Tarrio, cuxa xeografia dominial, como ben se ve no mapa que adxuntamos, se amolda perfectamente á existente na Casa de San Fiz.

En resumidas contas, a Casa de San Fiz levou a cabo entre 1580 e 1792 un total de 857 mercas, o que implica unha média de 1,8 por ano, con un desembolso absoluto de 9.040 .171 maravedis.

\section{OUTRAS CONSIDERACIÓNS}

Imaxinamos aos nosos petrúcios inseridos no negócio das mercavendas, apresentandose asi a propria actividade notarial como un inequívoco síntoma de alta posición social. Non en van, a inmiscusión contínua no mercado da terra implica un activo coñecimento das circunstancias deste e un certo controlo da comunidade, xa que o endevedamento campesiño figura entre as principais causas deste trafego. De aí que as élites foran as mais asíduas visitantes das escribanias. Os dados de Compostela son sinificativos, pois ali o $3^{\prime} 5 \%$ da populación orixinou o $31 ' 5 \%$ das actas notariais, de xeito similar a como realizan os formadores do noso dominio ${ }^{11}$.

Revisado o proceso inversor, se apresentan as constantes e problemas que posue o tratamento das mercas en famílias fidalgas. Asi, por exemplo, coñecélo ritmo de merca-vendas de terras a traverso dos arquivos nobiliares resulta mais complexo que facendoo co valeirado dos fondos de protocolos, habida conta de que non tódala documentacion relativa a vendas depositada no arquivo que manexamos garda relacion directa cos vinculeiros da família. Ou sexa, que en contra do que caberia agardar, non tódalas

${ }^{11}$ EIRAS ROEL, A; "Las élites urbanas de una ciudad tradicional: Santiago de Compostela a mediados del siglo XVIIIs; In II Coloquio de metodología histórica aplicada; Universidade de Santiago, 1984, p.119.

"CUADERnOS DE estudios GALLEGOS", Tomo XLII, Fascículo 107, Santiago 1995. 
mercas son efectuadas polos vinculeiros da casa, nen sequer por familiares directos ou indirectos a estes ${ }^{12}$. Das 1081 escritas de venda rexistradas temos identificadas 857 , quer dicer un $79,3 \%$, entre as cais incluimos aquelas realizadas por familiares en diverso grao dos vinculeiros pois alguns deles exercen como axentes patrimoniais do petrúcio. É importante facer esta salvedade en aras á metodoloxia, porcanto a pesares de que no tratamento estatístico incluímos únicamente as mercas efectuadas por membros da casa, resulta desconcertante a aparición de persoas alleas á mesma, se ben isto parece ter unha explicación lóxica ${ }^{13}$.

No relativo ao obxecto da venda, son na sua maioria alodios, rendas e casas, aptos de ser cedidas posteriormente en foros ou arrendos por parte do mercador, en moitas ocasions ao próprio vendedor da propriedade ${ }^{14}$. Mais do $97 \%$ das propriedadẹs están libres de pensión a directos

\footnotetext{
${ }^{12}$ No seu estudo sobre os arquivos nobiliários Olga GALLEGO concluiu que «...en ocasións por causas moi diversas incorporaronse outros fondos totalmente alleos á família, como acontece nas tutelas e testamenteiros desempeñados por algun membro da nosa familia, que poden dar orixe á incorporación destes arquivos a un arquivo familiar co que non manteñen nengunha relacion de parentesco...». In GALLEGO, $\mathrm{O}$; «Os arquivos da nobreza e o seu tratamento arquivísticon; In Conservá-la memória, Arquivo do Reino de Galicia, A Coruña, 1993, p.68

${ }^{13}$ Non existe unha explicación única senón múltiple: por unha parte atopamos protocolos que incluen mercas de terras circundantes ás da familia, de forma que ou ben estariamos ante un controlo documental das transferencias imobiliarias en zonas dominadas territorial ou xurídicamente polos vinculeiros, ou mais ben ante o acaparamento de tódala documentacion referente a aquelas propriedades que pasaron finalmente a engrosálo património familiar, como é o caso de moitas leiras próximas a este [ARG, FP, Leg.7, Fol.2].

Nesta liña tamén constatamos protocolos que conteñen vendas de terras que non nesa venda, pero si en posteriores irán parar ao vínculo, e que polo tanto introducen nomes de mercadores e vendedores descoñecidos para o investigador [ARG, FP, Leg.52, Fol.2]. A posibilidade de que a nosa familia acollera a documentación relativa a preitos por terras que aconteceran no seu señorio xurisdicional non nos convence, pois a documentación non identificada se corresponde tamén a zonas imunes do mesmo. De aí que nos inclinemos a considerar que estes protocolos respostan a un exaustivo controlo da propriedade da terra, incluso previa á incorporación por parte da familia.

${ }^{14}$ Vid. por exemplo: ARG, FP, Leg.21, Fol.1
}

"CUADERNOS DE ESTUdiOS GALLEGOS", Tomo XLII, Fascículo 107, Santiago 1995. 
domínios ${ }^{15}$, correspondendose unha pequena parte a herdanzas $-1,6 \%$ - e un $36,92 \%$ a rendas (TAVOA $\mathrm{N}^{\circ} 2$ ). As modalidades destas últimas semellan ser duas, por unha parte nos atopamos cunha pequena porcentaxe de rendas que vendense na sua totalidade, ou sexa, abranguendo a totalidade do dominio directo e constituindose, xa que logo, en autenticas vendas de foros ${ }^{16}$, e que para San Fiz suman un $8,91 \%$ do total. Pero a meirande parte das mercas de rendas se corresponden con porcións de foros, tal e como podemos ollar en casos paradimáticos onde se merca parte dunha renda, e posteriormente se volta a mercar un anaco maior ${ }^{17}$. Consideramos que estas transaccións deben de ser consideradas porque ainda que non supoñen a posesión dun foro, si implican a percepción dunha pensión, xunto á cal se pode adxuntar unha hipoteca sobre a propriedade. Para valorar estas rendas é fundamental entendéla territorialidade anexa a moitas delas, a cal non sempre se especifica claramente ${ }^{18}$, pero si indirectamente cando se fai expresión minuciosa da propriedade e do lugar de onde provén a renda en cuestión. As variedades poden ser múltiples, dende pequenas propriedades vendidas por posuir un domínio directo moi repartido $^{19}$; vendas de propriedades que logo se ceden en foro ao vendedor

${ }^{15} \mathrm{O}$ cal indica que a pequena propriedade campesiña estava relativamente extendida nalgunhas bisbarras galegas. Asi, alomenos $1 / 4$ da superficie cultivada e ata un $40 \%$ en ocasións é conceptuada no Catastro de Ensenada como pequena propriedade parcelaria. Coidamos que os altos indices de protocolarización de merca-vendas, que se prolongan ao longo do Antigo Rexime, son un indicio desta realidade. In SAAVEDRA, P; A Galicia do Antigo Rexime, economia e sociedade; In Historia de Galicia, Hércules, A Coruña, 1993, p. 364

${ }^{16}$ Un exemplo temo-lo nunha venda de 1602 efectuada por Pedro Fernández de San Julián ao bacharel Pedro Vázquez de Neira, segundo a cal o primeiro vendelle ao segundo «...dos fanegas de trigo por la medida de Avila segun se le pagaban de renta por la cortiña sita abajo de la fuente de la Magdalena y junto al primer portal y puerta del agro del palacio de Miraflores...». ARG, FP, Leg. 7, Fol. 17

${ }^{17} \mathrm{Asi}$, en 1584 Fernando de Galdo Herrador vendeu-lle ao coengo Pedro Ares de Neira «...dos fanegas de pan de renta sobre el lugar llamado da laja que labrava Bartholome da Laja y porque le pagaba anualmente doce fanegas de centeno, un puerco cebado y otros servicios...»; meses mais tarde o mesmo vendedor vendia-lle ao mesmo mercador «...una fanega mas de pan de renta sobre el expresado lugar...»; repetindo-se a operacion un ano mais tarde con outra fanega de pan, e meses despois con outras duas. ARG, FP, Leg.7, Fol.17

${ }^{18}$ Un exemplo onde si fai-se vemolo en ARG, FP, Leg. 52, Fol. 1

${ }^{19}$ ARG, FP, Leg. 52, Fol. 1

"CUADERNOS DE ESTUDIOS GALLEGOS", Tomo XLII, Fascículo 107, Santiago 1995. 


\begin{tabular}{|c|c|c|c|c|c|c|c|c|c|}
\hline RENDAS & $\begin{array}{l}12 \\
42,8 \% \\
\end{array}$ & $\begin{array}{l}18 \\
14,28\end{array}$ & $\begin{array}{l}47 \\
44,38 \\
\end{array}$ & $\begin{array}{l}41 \\
8,28\end{array}$ & $\begin{array}{l}98 \\
50,28 \\
\end{array}$ & $\begin{array}{l}26 \\
20,68 \\
\end{array}$ & $\begin{array}{l}39 \\
36,41 \\
\end{array}$ & $\begin{array}{l}\delta \\
27,22 \\
\end{array}$ & $\begin{array}{l}287 \\
36,98\end{array}$ \\
\hline CASAS & 0 & $\begin{array}{l}7 \\
5,58\end{array}$ & $\begin{array}{l}3 \\
2,88\end{array}$ & 1,58 & $\begin{array}{l}7 \\
3,5 \%\end{array}$ & $\begin{array}{l}8 \\
8,38\end{array}$ & $\begin{array}{l}4 \\
3,7 \%\end{array}$ & $\begin{array}{l}5 \\
22,78 \\
\end{array}$ & $\begin{array}{l}35 \\
4,5 \% \\
\end{array}$ \\
\hline LUGARES & $\begin{array}{l}4 \\
14,28 \\
\end{array}$ & $\begin{array}{l}29 \\
238 \\
\end{array}$ & $\begin{array}{l}16 \\
15 \% \\
\end{array}$ & $\begin{array}{l}6 \\
96\end{array}$ & $\begin{array}{l}10 \\
9,28\end{array}$ & $\begin{array}{l}7 \\
5,5 \%\end{array}$ & $\begin{array}{l}2 \\
2,8 \% \\
\end{array}$ & $\begin{array}{l}4 \\
18,18 \\
\end{array}$ & $\begin{array}{l}87 \\
11,28\end{array}$ \\
\hline LEIROS & $\begin{array}{l}7 \\
258\end{array}$ & $\begin{array}{l}34 \\
26,98\end{array}$ & $\begin{array}{l}10 \\
9,4 x\end{array}$ & $\begin{array}{l}10 \\
15,1 \%\end{array}$ & $\begin{array}{l}28 \\
14,38\end{array}$ & $\begin{array}{l}4 i \\
32,5 \%\end{array}$ & $\begin{array}{l}21 \\
19,68\end{array}$ & $\begin{array}{l}4 \\
18,18\end{array}$ & $\begin{array}{l}155 \\
19,98\end{array}$ \\
\hline PRADOS & $\begin{array}{l}i \\
3,5 \% \\
\end{array}$ & $\begin{array}{l}1 \\
4,78 \\
\end{array}$ & $\begin{array}{l}1 \\
0,9 \% \\
\end{array}$ & $\begin{array}{l}1 \\
1,5 \% \\
\end{array}$ & $\begin{array}{l}8 \\
4,3 \% \\
\end{array}$ & $\begin{array}{l}9 \\
7,18 \\
\end{array}$ & $\begin{array}{l}10 \\
9,3 \%\end{array}$ & 0 & $\begin{array}{l}31 \\
3,9 \% \\
\end{array}$ \\
\hline SOUTOS & $\begin{array}{l}1 \\
3,5 \%\end{array}$ & $\begin{array}{l}5 \\
6,8 \% \\
\end{array}$ & $\begin{array}{l}8 \\
7,5 x \\
\end{array}$ & 0 & $\begin{array}{l}3 \\
1,58\end{array}$ & $\begin{array}{l}\hat{\imath} \\
1,5 \%\end{array}$ & $\begin{array}{l}? \\
1,8 \% \\
\end{array}$ & 0 & $\begin{array}{l}22 \\
2,82 \\
\end{array}$ \\
\hline VIÑAS & 0 & $\begin{array}{l}9 \\
7,18 \\
\end{array}$ & $\begin{array}{l}12 \\
11,32 \\
\end{array}$ & $\begin{array}{l}2 \\
38 \\
\end{array}$ & $\begin{array}{l}18 \\
9,28 \\
\end{array}$ & $\begin{array}{l}15 \\
11,98 \\
\end{array}$ & 0 & 0 & $\begin{array}{l}56 \\
\therefore, 28 \\
\end{array}$ \\
\hline HERDANZA & 0 & $\begin{array}{l}2 \\
i, 58 \%\end{array}$ & $\begin{array}{l}2 \\
1,8 \%\end{array}$ & $i$ & $\begin{array}{l}2 \\
1 \% \\
\end{array}$ & $\begin{array}{l}2 \\
1,5 \% \\
\end{array}$ & $\begin{array}{l}4 \\
3,78 \\
\end{array}$ & 0 & $\begin{array}{l}13 \\
1,6 \% \\
\end{array}$ \\
\hline MULTTPLE & $\begin{array}{l}2 \\
7,18\end{array}$ & $\begin{array}{l}17 \\
13,48\end{array}$ & $\begin{array}{l}5 \\
4,78 \\
\end{array}$ & $\begin{array}{l}3 \\
4,5 \% \\
\end{array}$ & $\begin{array}{l}? \\
3,5 \%\end{array}$ & $\begin{array}{l}11 \\
8,7 \% \\
\end{array}$ & $\begin{array}{l}22 \\
20,58 \\
\end{array}$ & $\begin{array}{l}? \\
9 \% \\
\end{array}$ & $\begin{array}{l}87 \\
8,8 \%\end{array}$ \\
\hline VARIA & $\begin{array}{l}1 \\
3,5 \% \\
\end{array}$ & $\begin{array}{l}3 \\
2,36 \\
\end{array}$ & $\begin{array}{l}2.8 \\
1,8 \% \\
\end{array}$ & $\begin{array}{l}i \\
i, 5 \% \\
\end{array}$ & $\begin{array}{l}6 \\
3 \% \\
\end{array}$ & $\begin{array}{l}5 \\
3,9 \% \\
\end{array}$ & $\begin{array}{l}2 \\
1,8 \% \\
\end{array}$ & $\begin{array}{l}1 \\
4,5 \% \\
\end{array}$ & $\begin{array}{l}21 \\
3,7 x \\
\end{array}$ \\
\hline TOTAL & $\begin{array}{l}28 \\
1008\end{array}$ & $\begin{array}{l}126 \\
1008\end{array}$ & $\begin{array}{l}106 \\
100 x\end{array}$ & $\begin{array}{l}66 \\
100 x\end{array}$ & $\begin{array}{l}195 \\
1008\end{array}$ & $\begin{array}{l}126 \\
1008\end{array}$ & $\begin{array}{l}107 \\
100 \%\end{array}$ & $\begin{array}{l}22 \\
1008\end{array}$ & $\begin{array}{l}776 \\
1008\end{array}$ \\
\hline
\end{tabular}

TABOA 2.

TIPOS DE BENS MERCADOS POLA CASA DE S. FIZ DE ASMA (1575-1750) 
-actuacion típica para os casos de endevedamento ${ }^{20}-$, ou casos de vendas que incluen nun mesmo protocolo propriedades numerosas ${ }^{21}$.

É preciso insistir na similitude mais que formal existente entre as mercas de rendas e os censos, habida conta de que a operacion que se produce nun e noutro caso resulta paralela: a cesión duns cartos a troques dunha renda en espécie que actua a xeito de interese; tan só a asimilación estrita aos censos adoece da definición concreta da sua calidade de redimibles, e isto é asi porque a renda o que busca é perpetuarse «para siempre xamas», de aí non só a utilización desta cláusula nos protocolos, senon tamén o detallismo con que se sinala o lugar concreto de procedéncia da renda, en que se vai pagar ou incluso onde debe de ser posta, etc...22.

A evolución diacrónica e a presion sobre a propriedade da terra podemola ollar brevemente facendo a micro-história do lugar das Flores no couto de Ombreiro. Posuimos unha pequena documentación deste a partires de meiados do século XVI, atopandonos con dez escritas de venda, boa parte delas protagonizadas por Jácome Flores, labrego que posue numerosas propriedades que vende sucesivamente ao longo do século a prol fundamentalmente de Basco Rois, indivíduo ao que vemos mercando diversas herdades e rendas no lugar entre 1572 e 1577 . Un ano antes desaparece de cena este inversor e vese sustituído por Gómez Núñez de Gayoso, a quen observamos mercando posesións de Jácome Flores e Domingo Regueiro, os cais venden pequenas porcentaxes das suas

\footnotetext{
${ }^{20}$ ARG, FP, Leg.21, Fol.1.

${ }^{21}$ ARG, FP, Leg.21, Fol.7

${ }^{22}$ A pesares do reducido da amostra é interesante observar como para o Xallas o
} $60^{\prime} 7 \%$ das rendas as mercan burgueses ou fidalgos, e o 17 ' $8 \%$ entidades eclesiásticas, mentres que o $21^{\prime} 5 \%$ xentes do comun. BARREIRO MALLÓN, B; La jurisdicción de Xallas en...; op cit. p.501.

No caso do Salnés, considerouse o desenrolo das vendas de rendas entre 1650 e 1750 como unha resposta mais á presión demográfica (...) Feitas a modo dun censo tosco, o carácter fortemente especulativo desta forma de empeño a convertiria tamén en recurso de última necesidade. PÉREZ GARCÍA, J.M; Un modelo de sociedad rural de Antiguo Régimen en la Galicia costera: La península del Salnés; Universidade de Santiago, 1979, p.364

De aí tamén a cativeza das rendas vendidas, responsáveis en grande parte da hiperfragmentacion do terrazgo. En Mondoñedo as explotacións campesiñas chegaronse a reducir entre os séculos XVII e XVIII entre un 10 e un 40\%. SAAVEDRA, P; Economía, politica y sociedad en Galicia. La provincia de Mondoñedo, 1480-1830; Xunta de Galicia, Santiago, 1985, p.219.

"CUADERNOS DE ESTUDIOS GALLEGOS", Tomo XLII, Fascículo 107, Santiago 1995. 
propriedades segundo as circunstancias a que se ven sometidos. O proceso de inversión nas terras continua no primeiro cuarto do século XVII e deten-se até os anos 1665-66, onde se documenta unha febril actividade de vendas, -entre as que destacan as realizadas por Francisco López en 1666 , quen nun primeiro momento vende boa parte das suas propriedades e meses mais tarde diante das dificultades económicas fai o mesmo cunha pequena renda- que revirten na sua meirande parte a Maria del Castillo Neira. Este proceso, que resposta a unha crise de subsisténcia, modera-se camiño do XVII até que no 1699 documentamos a actividade inversora de José Benito de Prado, quen en 1703 somete ao lugar a un apeo, logo do cal parte do mesmo é arrendado en 1710 a Santiago Saja por un espazo de 9 anos, transcorridos os cais o vinculeiro decide aforálo mesmo a Antonio Burgo cunha pension anual de 10 fanegas de centeo.

A micro-história do lugar correspondese a groso modo coa macrohistória dominial na que logo dun agudo proceso de expropriacion campesiña na segunda metade do XVI que se completa con diversas crises da propriedade campesiña do XVII, continua unha actualizacion das rendas e o controlo da propriedade por parte do domínio de José Benito de Prado no século XVIII.

Con estas mercas a família pretende asentar o carácter rendista da sua economia e emporiso renunciase á posesion do domínio útil da propriedade, que tan pronto como é adquirido cedese en foro ou en arrendo coa intención de só perceber a renda pertinente.

A circunstancia de que o noso dominio sexa un mais dos varios que compiten no Antigo Réxime pola sua expansión reflictese no tipo de mercas realizadas. Isto é asi porque observamos un correlato entre a progresiva perda de protagonismo da propriedade alodial e a porcentaxe de mercas de rendas sobre o total, entendendose que o aumento desta porcentaxe correrá inversa á disminución das inversións en propriedade alodial. $\mathrm{Na}$ TÁVOA N ${ }^{2} 2$ manifestase unha menor importancia das mercas de rendas no século XVI que no século XVII. Os dados que apresentamos para o área de San Fiz son parellos aos que atopou Villares nas mercas realizadas polo mosteiro de San Salvador de Chantada entre 1556 e 1582, das cais un $58^{\prime} 7 \%$ se corresponden a rendas, mentres que nas mercas realizadas por Estevo Tenreiro Varela no século XVI a porcentaxe ascende ao $57^{\prime} 14 \%$. Pola sua parte, a proporción de lugares mercados reducese considerablemente dende o $18,6 \%$ de $1550-1600$ ao $12 \%$ de $1600-1650$.

A estas alturas da exposición, a importáncia das mercas de terras na formación deste domínio fidalgo danlle senso a reveladoras informacións

"CUADERNOS DE ESTUDIOS GALLEGOS", Tomo XLII, Fascículo 107, Santiago 1995. 
como a fornecida por GONZÁLEZ DE ULLOA no século XVIII ao comentar que:

«...o méio seguro, indefectíble para dar fin, cabo e arruinar unha freguesia é que o abade comece e prosiga a mercar nela, pois con poucos cartos mercará moito...»

González de Ulloa observa como en ocasións os simples gastos dun funeral e as dévedas por el contraídas determinaron a venda de parcelas, saindo de aí alguns vínculos ${ }^{23}$.

Este dato insiste na importante dimensión social das mercas de terras. Nada mellor que as transaccións de rendas que se desenrolan ao longo do Antigo Réxime para comprendé-la dimensión do endevedamento campesiño. Temos testemuñas deste proceso non só con casos nos que se venden rendas de xeito repetitivo e insistente en anos consecutivos, o cal indicaria unha situacion crítica por parte do campesiño e colocaria as vendas de rendas como unha saída ocasional, pontoal e para saír do paso -de aí as vendas de poucas cantidades de rendas un ano tras outro-. Tamén temos o exemplo dos testamentos de personaxes da nosa documentación, como Juán Fernández, Men Vásques de Chantada e outros, nos que aparecen numerosas rendas en memórias de dévedas que non son mais que consecuéncia de mercas realizadas aos pagadores.

No caso da Asturias este xeito de actuar parece ter sido moi comun pois como explica Barreiro, en tódolos casos coñecidos de fundacións de vínculo produxose préviamente unha notable inverson en bens raíces ${ }^{24}$. Unha pequena cata feita polo mesmo autor na bisbarra do Xallas confirmaba esta tendéncia para o área noroccidental da Galiza, observandose como boa parte dos mercadores eran cregos ou xentes con Don ${ }^{25}$.

\footnotetext{
${ }^{23}$ In GONZÁLEZ DE ULLOA; Descripción de los estados de la casa de Monterrey en Galicia; C.E.G. Anexo IV, Santiago, 1950, p.158

${ }^{24}$ Acompañados ou non de elevadas cantidades de cabezas de gando e cáseque sempre de xuros ou cárregos municipais que incorporaron ao morgado. BARREIRO MALLÓN, B; «La nobleza asturiana ante la muerte y la vida»; In Actas del II Congreso de metodologia histórica aplicada, Universidade de Santiago, 1984, p.58.

${ }^{25}$ De 150 contratos entre a segunda metade do XVII e o XVIII, o reparto seria o seguinte: Labradores $26^{\prime} 6 \%$; cregos $13{ }^{\prime} 31 \%$; fidalgos e burgueses $42{ }^{\prime} 6 \%$ e indefinidos $17^{\prime} 6 \%$. As causas das vendas serian no $61^{\prime} 1 \%$ por pura necesidade. De aí que como vese
} 
Como adoita a ser habitual nestes casos, o promédio de vendas aumentaria de xaneiro a máio, baixando posteriormente entre xuño e agosto e proseguendo unha terceira etapa de índices médios ${ }^{26}$.

Este fenómeno en absoluto é alleo a outros procesos de formación dominial acaecidos fóra da Galiza, como constatou García SANZ para o caso de Segovia xunto con outros historiadores ${ }^{27}$. Coincidimos, xa que logo, co apontado por Pegerto SAAVEDRA para Mondoñedo no senso de que os principais beneficiados da expropriación campesiña foron os fidalgos e os seus ascendentes ${ }^{28}$.

Para o exemplo que estamos a tratar, a comprobación desta hipótese é factible ao traverso da inversión en maravedís efectuada pola casa nos principais anos da sua actividade. Deste xeito decididimos agrupá-las inversións por anos, deflactando posteriormente as mesmas en relación co prezo do centeo na comarca da Ulla $^{29}$ para desta sorte obter un índice homoxéneo, que a falla dunha deflacción mais axeitada para as terras de Lugo, alomenos nos permita intuilas tendencias globais.

Os dados tirados anualmente permiten comprobar como a inversión variaba nunha alternancia que incluia temporadas de 5,6 ou 7 anos de

no caso de San Fiz, a meirande parte das fincas vendidas sexan de dimensions reducidas, nunca superiores aos tres ferrados, suficientes para saír adiante en épocas de apuros. BARREIRO MALLÓN, B; La jurisdicción de...; op cit. p. 500

${ }^{26}$ vid TILVES DIZ, J; «Las compra-ventas de tierras en la comarca compostelana en los siglos XVII-XVIII: Planteamiento metodológico y resultados de conjunto»; In II Coloquio de Metodología Histórica Aplicada, Universidade de Santiago, 1984, p. 437

${ }^{27}$ García Sanz non duvida colocar á cabeza dos mecanismos de concentración de terras á merca de parcelas e as operacións de creto aos campesiños «...que perdian a propriedade da sua terra no trance e nas donacións e mandas pias ás institucions eclesiásticas...) (vid. GARCÍA SANZ, A; Desarrollo y crisis del Antiguo Régimen en Castilla la Vieja. Economia ysociedad en tierras de Segovia, 1500-1814, Akal, Madrid, 1977, p. 270). O mesmo se ollou para o caso valenciano de Alfara, onde durante o Antigo Réxime o señorio mercou incesantemente fanegas de terra, atestiguandose tamén un endevedamento campesiño prévio sempre á venda (in PESET \& GRAULLERA \& FERNANDA; «El señorio de Alfara del Patriarca, 1601-1845»; In E.H.C.P.V. $\mathrm{n}^{\circ} 2$, Universitat de Valencia, 1981, pp. 38-40). Tamén as casas grandes recorriron á merca de terras e señorios de forma contínua ao longo da sua história (vid CARRASCO MARTÍNEZ, A; El régimen señorial en la Castilla moderna: las tierras de la Casa del Infantado en los ss.XVII y XVIII; Universidad Complutense, Madrid, 199I, p.243).

${ }^{28}$ In SAAVEDRA, P; Economia, política y sociedad ...; op cit. p. 442

${ }^{29}$ Datos obtidos de: REY CASTELAO, O; Aproximación a la historia rural en la comarca de la Ulla (siglos XVII y XVIII); Universidade de Santiago, 1981, p. 263

"CUADERNOS DE ESTUDIOS GALLEGOS", Tomo XLII, Fascículo 107, Santiago 1995. 
actividade afastadas por anos de parálise. A comprobación de se existe algunha relación entre estes dentes de serra e o prezo do cereal poderia revelar ou non unha influencia decisiva da coxuntura agrícola no ritmo inversor da Casa, para o cal decidimos comparar no GRÁFICO $\mathrm{N}^{\circ} 3$ a inversión en mercas deflactada, co prezo do centeo na Ulla.

O primeiro que se salienta é que non existe unha relación directamente proporcional entre o aumento do prezo do centeo e a baixa ou a alza no ritmo e cuantia das inversións, existindo épocas como a de 1687 ou 1695 onde os prezos altos se corresponden con baixas importantes na contratación de mercas e viceversa. Non embargantes, a tendéncia xeral non é a citada; quer dicer, as temporadas de prezos altos non adoitan a se corresponder con baixas na inversión das terras, de xeito que por norma xeral se observa como os anos de prezos elevados dan orixe a un incremento mais ou menos sinificativo nos maravedis invertidos pola família na sua formación dominial. Asi se ve perfectamente nos alzas de 1613, 1617, 1631, $1643,1653,1675,1680,1699,1722$ ou 1725 . Desta forma, serian as temporadas de carestia, quer dicer de prezos altos, nas que a Casa tenderia xeralmente -que non automáticamente- a invertir mais cartos na merca de terras. A que se debe isto?.

Coidamos que a explicación pasa polo mecanismo de extracción de beneficios. Este, estaba maioritáriamente na percepción de rendas anuais nunha cuantia que en 1790 consistia en 268 hls de cereais, 249 de viño, 14.926 mvs e 368 servizos. Sabemos que esta cantidade era similar á que cobraba a Casa un século denantes, de xeito que se comprende desta sorte a importáncia que tiña a venda de cereais á hora da extracción do benefício económico, se consideramos lóxicamente que tal cantidade seria moi superior á que necesitarian os vinculeiros para seu consumo e o dos seus contratados. Se temos en conta que esta venda de rendas se regulaba segundo a alza ou baixa dos prezos, potenciando as saídas ao mercado en meses de soldadura e armaceando stocks dun ano para outro, non é dificil concluir que nas épocas de carestia, os prezos altos e a dispoñibilidade de reservas implicarian pingues beneficios para os vinculeiros.

Segundo os dados expostos na gráfica, no caso de San Fiz parece cumplirse a máxima labroussiana que indica que o alza de prezos compensa con creces a baixa da produtividade e traduce un aumento da renda ${ }^{30}$.

${ }^{30}$ Vid. LABROUSSE, E; Fluctuaciones económicas e historia social; Tecnos, Madrid, 1980, p.192

"CUADERNOS DE ESTUdIOS GALLEGOS", Tomo XLII, Fascículo 107, Santiago 1995. 


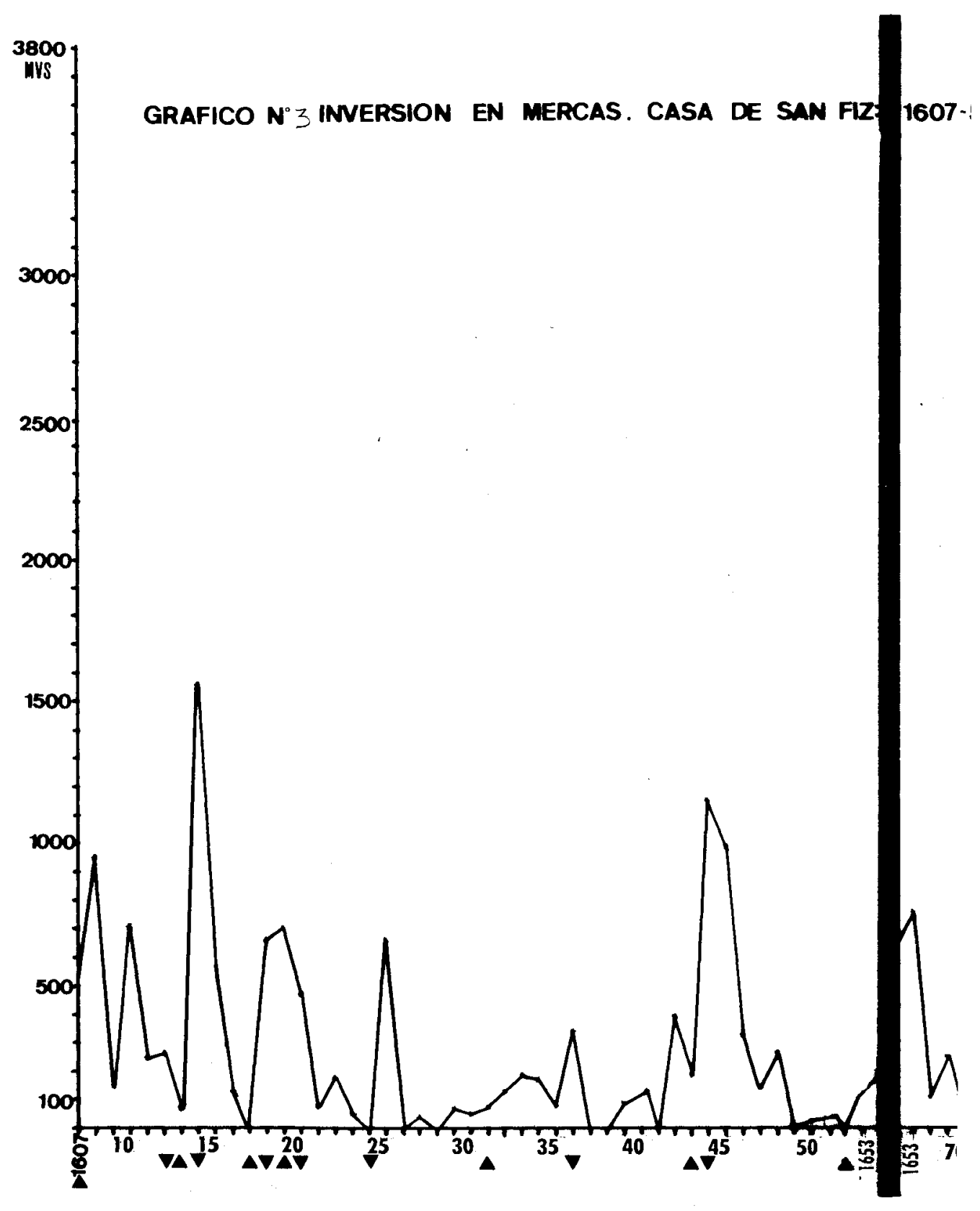

GRÁFICO 3: INVERSIÓN EN MERCAS. CASA DE SAN 
-1726. En wrs deflactages do gented un vila.

PRELOS ALTOS

PRELOS MIXOS

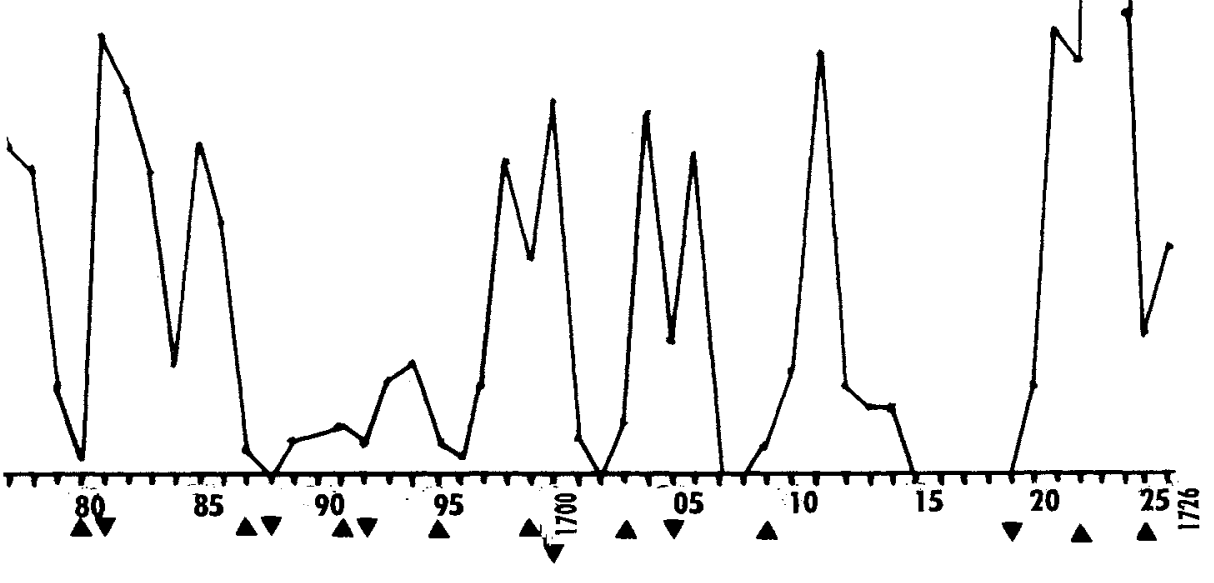

'-53/ 1668-1726. En MVS deflactados do Centeo na Ulla. 
Nesta regra introducese a variable da produtividade, a cal evidentemente baixaria en épocas de crises de subsistencias e similares. Esta baixa da produtividade influiria positivamente na economia dos nosos fidalgos de duas formas: A) Indirectamente, vendose obrigados os campesiños a acodir ao mercado e mercar o cereal caro ao non ter reservas para o consumo e tampouco para a satisfacción das rendas; B) Tendendo a vender mais terras e rendas para sacar capital suficiente co que acodir ao mercado. Evidentemente desta expropriación os próprios facendados serian os mais beneficiados.

Entendese agora que a grave crise de subsistencias de $1710^{31}$ se acompañara para o domínio de San Fiz dun incremento importante nas cantidades desembolsadas en transaccións. A bonanza dos poderosos se correspondia co desolador panorama que ofrecian para aqueles anos as terras de Galicia:

«...Me traspasa el corazón ver en nuestra ciudad, segunda y nueva Jerusalén, trasladada en trenos lastimosos la lamentación de Jeremías; un pueblo que gime y se lastima por la carestia de pan; unos que agonizan sufocados del hambre; otros que se caen de miseria; los niños palpitando entre el árido pecho de la madre; los párvulos pidiendo pan, sin haber quien lo distribuya. Mucho me duele y conduele tan funesta cala$\operatorname{midad} . . .{ }^{32}$.

A pesares dos indícios apontados, non podemos entendélo rimo das mercas e as inversións económicas verbo únicamente dos prezos e da oferta e da demanda, non só polo perigoso da adopción de unha única perspectiva $^{33}$, senón pola importáncia que na família teñen outros factores como a personalidade dos indivíduos ou as vicisitudes da estratéxia social, fundamentalmente o matrimonio. Non é obxecto deste artigo pormenorizar nestes aspectos, pero sirva a sua mención para precisar que na administración dominial se percebe con claridade o maior encono de determinados vinculeiros como José Arias ou José Benito de Prado fronte ao abandono doutros como Pedro Vázquez ou Francisco Arias. Por outra parte,

${ }^{31}$ Vid. REY CASTELAO, O; Aproximación a la...; op cit. p.293

${ }^{32}$ Declaracións do arcebispo Monroi en 1710 recopiladas por LÓPEZ FERREIRO, A; Historia de la S.A.M.I. de Santiago de Compostela; Santiago, 1905, p.251

${ }^{33}$ Vid ao respecto, LEVI, G; La herencia inmaterial; Nerea, Madrid, 1990, p.98

"CuAdernos De eSTUdios GallegOS", Tomo XLII, Fascículo 107, Santiago 1995. 
salientemos outravolta a súpeta detención nas inversións da Casa con Vicente Maria de Prado, precisamente aquel cuxo casamento implicou a incorporación do pazo viciño de Tarrio. Quer dicer, que independentemente da oferta e da demanda, xogan outros factores por veces moi importantes, o cal non obsta para considerálas inversións en terras como a primeira e, por isto, importantísima estratéxia familiar de formación dominial, non só en San Fiz, senón tamén noutras casas fidalgas.

"CUADERNOS DE ESTUdIOS GALLEGOS", Tomo XLII, Fascículo 107, Santiago 1995. 